\title{
Ethical problems in the use of algorithms in data management and in a free market economy
}

\author{
Rafał Szopa ${ }^{1}$ (D)
}

Received: 23 July 2021 / Accepted: 23 November 2021

(c) The Author(s) 2021

\begin{abstract}
The problem that I present in this paper concerns the issue of ethical evaluation of algorithms, especially those used in social media and which create profiles of users of these media and new technologies that have recently emerged and are intended to change the functioning of technologies used in data management. Systems such as Overton, SambaNova or Snorkel were created to help engineers create data management models, but they are based on different assumptions than the previous approach in machine learning and deep learning. There is a need to analyze both deep learning algorithms and new technologies in database management in terms of their actions towards a person who leaves their digital footprints, on which these technologies work. Then, the possibilities of applying the existing deep learning technology and new Big Data systems in the economy will be shown. The opportunities offered by the systems mentioned above seem to be promising for many companies and-if implemented on a larger scale—-they will affect the functioning of the free market.
\end{abstract}

Keywords Volatility $\cdot$ Free market $\cdot$ Predictability $\cdot$ Algorithms $\cdot$ Real person $\cdot$ Digital person

\section{Introduction}

We will start by discussing the concept of "person", reaching back to ancient and medieval thought, and then we will move to the twentieth century to show how much the approach to man has changed, especially in terms of spirituality and freedom. The creation of the first artificial neural networks and treating them as a reflection of the brain's operation made a real person have their digital double. This digital human image has been used, for example, to predict consumer preferences and create psychological profiles of Facebook users. Here arises the problem of imposing unchanging models on the changing human reality and treating man as if they were a thing. The second serious problem is likely to be access to information, the possession of which will be crucial to compete with companies with a near-monopoly position. Equal access to technological systems will be essential to maintaining a free market economy.

Rafał Szopa

rafal.szopa@pwr.edu.pl

1 Department of Humanities and Social Sciences, Faculty of Management, Wroclaw University of Science and Technology, Wrocław, Poland

\section{Deep learning-historical and philosophical background}

The idea that the machine can learn and be like a human being in terms of intelligence was initiated by Warren McCulloch and Walter Pitts. These authors showed that the biological neural network of the brain can be summarized in logical terms. They write: "Physiological relations existing among nervous activities correspond, of course, to relations among the propositions" (McCulloch and Pitts 1943, p. 117). This approach was groundbreaking in the sense that it allowed the brain to be treated like a "computer". The brain became computable and its neural activity could be represented in the language of logic and mathematics. This had consequences. As the authors write, "Specification of any one time of afferent stimulation and of the activity of all constituent neurons, each an 'all-or-none' affair, determines the state. Specification of the nervous net provides the law of necessary connection whereby one can compute from the description of any state that of the succeeding state (...)" (McCulloch and Pitts 1943 , p. 129). It also follows that our knowledge of the world is limited, as all our cognitive processes take place in the brain within the neural network (McCulloch and Pitts 1943, pp. 129-131). 
Perhaps the most important lesson to be drawn from McCulloch and Pitts' work is that "'Mind' no longer 'goes more ghostly than a ghost'" (McCulloch and Pitts 1943, 132). The person is no longer viewed as having spiritual qualities and is reduced to the material level. The work of Mculloch and Pitts opened a wide discussion on the essence of the mind as well. CTM (Computational Theory of Mind) proponents argue that the mind is like a Turing machine (Rescorla 2020). Connectionists oppose CTM, saying that neural networks are more suited to the nature of the mind and its operation, especially in terms of learning (Rescorla 2020). Hilary Putnam made a large contribution to the theory of mind in the 1960s. He argued that the human being and the Turing machine are comparable (Putnam 1960, p. 35). Hence machine functionalism. These three approaches, CTM, connectionism, and functionalism are still under discussion and have extensive literature on the subject. Therefore, I do not want to enter this discussion theoretically, but rather show that at least one of these approaches has become practically applied and has achieved impressive results-connectionism. The pioneering work of Mculloch and Pitts combined, in a sense, what we now call CTM and connectionism, but the latter approach has been used empirically and is still being developed. This does not mean, of course, that CTM or functionalism are not useful intellectual tools for explaining how the mind works. However, it seems that connectionism is capable of connecting CTM with machine functionalism. Moreover, connectionism is used today to develop computer technologies by providing specific solutions.

Deep learning is part of machine learning, but a more advanced technique. The main difference between them is that

"conventional machine-learning techniques were limited in their ability to process natural data in their raw form", while "deep learning methods are representation-learning methods with multiple levels of representation, obtained by composing simple but non-linear modules that each transform the representation at one level (starting with the raw input) into a representation at a higher, slightly more abstract level" (LeCun et al. 2015, p. 436).

Given the complexity of the human personality, deeplearning appears to be a more appropriate technique. Both machine and deep learning can be supervised and nonsupervised. In the first case, we teach the machine what we want it to learn. Applying this reasoning to personality traits, e.g. to the Big Five, we teach the algorithm what traits should be taken into account in order to obtain a picture of the personality traits that make up the Big Five. In the case of non-supervised learning, the trained algorithm itself decides which data to qualify and which to reject in order to get the same output. The non-supervised learning algorithm is used, e.g. by Facebook. Now, I want to present how such algorithms work.

The history of the use of algorithms to describe human behavior began in 1957, when the American psychologist Frank Rosenblatt introduced the term "perceptron", which was supposed to be a model of the brain (Rosenblatt 1961, p. 3). The currently applicable model of artificial neural networks is usually the so-called sigmoid neural networks. The perceptron concept had some limitations, which prevented it from accurately replicating the functioning of the biological neural network. Rosenblatt wrote: "A network consisting of less than three layers of signal transmission units, or a network consisting exclusively of linear elements connected in series, is incapable of learning to discriminate classes of patterns in an isotropic environment" (Rosenblatt 1961, p. 575). The design of the perceptron was so simple that it usually consisted of the so-called hidden layers, so there was the first (input) and second (output) layer. Such a structure would not allow the use of the deep learning method today. The author himself admitted that the three-layer model is the minimum, where we can omit data of lesser importance and teach the network to solve the problems we want. But "any discrimination problem can, in principle, be solved by such a system" (Rosenblatt 1961, p. 575). By adding subsequent layers, it was possible to deal with the problem of poor data generalization, speech recognition, and the basic meaning of nouns and verbs, but systems built even with many layers "are handicapped by a lack of a satisfactory "temporary memory', by an inability to perceive abstract topological relations in a simple fashion, and by an inability to isolate meaningful figural entities, or objects, except under special conditions" (Rosenblatt 1961, p. 577).

These problems can be overcome by the use of a network of sigmoid neurons. One of the main advantages of sigmoid neurons is that in input they do not need to be 0 or 1 ; similarly in output, but a number in between. This allows the neurons to learn (Nielsen, 8). Taking into account, for example, personality traits on the example of the five-factor model, which - as we will see-analyzes the Facebook algorithm, users decide on an input by clicking on Likes. If the algorithm were built on the basis of a perceptron neural network and steep function, each Like would get the value 0 or 1 , and it would or may not be associated with a specific personality factor. The final result would probably be quite quickly achievable, but also inaccurate. Meanwhile, oscillating between 0 and 1 allows for much greater accuracy and subtlety of the results. Thanks to this, the sigmoid neural network is also more resistant to errors and-in the case of, for example, the Facebook algorithm-the algorithm can take into account even irrelevant, at first glance, data, which results not only in greater accuracy but also resistance to "fraud" on the part of users. The sigmoidal network can 
also be very extensive and have a large number of so-called hidden layers, i.e. those between input and output. In other words, a Facebook user might want to trick the algorithm into mind-picking Likes that, if developed by the algorithm, would have given a different result than in a standard personality test. It is against such attempts of cheating that the algorithm is more resistant in the case of sigmoidal networks.

Backpropagation algorithm developed since the 1970s enables the capture of errors in the designed neural network, making it even more resistant to manipulation. Backpropagation algorithm is non-linear. It checks how the entire network works in terms of performance. The authors of the famous article on the backpropagation algorithm explain the matter as follows: "If there a fixed, finite set of input-output cases, the total error in the performance of the network with a particular set of weights can be computed by comparing the actual and desired output vectors for every case" (Rumelhart et al. 1986, p. 534). This means that the neural network and algorithms can be designed to run as the designer wants. Deep learning enables unsupervised learning of the net. However, this does not mean that when creating the digital personality of social media users, everything happens automatically. The users are co-authors of the network. Having a Facebook account with no activity, we start our digital life with a blank slate. By clicking on the "Like" we start building the first layer of the network. Over the years of clicking Likes, we build a huge network, a database about us, in which operates an algorithm designed to represent our personality traits. However, in order to the algorithm could "know" what to do, psychologists had to build a model, for example, the Big Five. Our digital personality is, therefore, the result of the work of psychologists, computer scientists and ourselves. Now let us see what the results are.

\section{Real and digital person}

All the issues discussed in this paper concern the issue of the person, because only then - I think so-can we speak of morality of economic systems. Moral considerations make sense in the perspective of a being that can suffer and benefit, who is aware of their situation. When speaking of economic systems or technologies, they concern directly human beings. In view of the whole spectrum of views on the concept of "person", it seems that one should choose those features of a person which seem to be most often emphasized: rationality and freedom. Joseph Ratzinger wrote that the concept of "person" is of Christian origin: "The concept of person, as well as the idea that stands behind this concept, is a product of Christian theology. In other words, it grew in the first place out of the interplay between human thought and the data of Christian faith and so entered intellectual history" (Ratzinger 1990, p. 439). It is worth noting that it is not about the dimension of religion only, but that religion inspired the theologians and philosophers of the time to deal with the problem of the person.

In antiquity and the Middle Ages, there were two wellknown definitions referring to the person by Boethius and Richard of St. Victor. Boetian definition says: persona est naturae rationalis individua substantia (Balthasar, 1986, p. 22). This definition emphasizes primarily human rationality. If we add to it Richard's definition - Persona divina est divinae naturae incommunicabilis existentia (P.L. 196, 944) - we get the image of a person who is not only rational, but also mysterious and free. The key phrase here is the expression"incommunicabilis". A person is a non-communicable existence of an individual nature (Biesaga 2014, p. 569). A person's individuality is not confined to acts that are performed by the person (Biesaga 2014, p. 569). This irreducibility of the person is extremely important because our digital footprint does not resemble the people we really are. However, it happens that companies obtain information about consumer preferences precisely on the basis of who we are not.

The first thing to realize is that algorithms are able to predict who we are, even if we do not reveal ourselves: "People may choose not to reveal certain pieces of information about their lives, such as their sexual orientation or age, and yet this information might be predicted in a statistical sense from other aspects of their lives that they do reveal" (Kosiński et al. 2013, p. 5802). It also turns out that computers are better at assessing personality traits than humans. Researchers write: "we show that computers' judgments of people's personalities based on their digital footprints are more accurate and valid than judgments made by their close others or acquaintances (friends, family, spouse, colleagues, etc.). Our findings highlight that people's personalities can be predicted automatically and without involving human social-cognitive skills" (Youyou et al. 2015, p. 1036). Moreover, Facebook Likes are very representative of the Big Five: "Why are Likes diagnostic of personality?" Exploring the Likes most predictive of a given trait shows that they represent activities, attitudes, and preferences highly aligned with the Big Five theory" (Youyou et al. 2015, p. 1037). The accuracy of the assessment of the user's personality by the algorithm exceeds that of humans:"computer models need 10, 70, 150, and 300 Likes, respectively, to outperform an average work colleague, cohabitant or friend, family member, and spouse" (Youyou et al. 2015, p. 1037). In general, the more Likes, the greater the accuracy of the algorithm (Youyou et al. 2015, p. 1037). Researchers indicate that the advantage of computers over people is the result of the fact that computers are able to collect a large amount of data, and the subject of the user, as well as the method of their collection based on statistical modeling and optimization, allows 
algorithms to constantly improve their accuracy (Youyou et al. 2015, p. 1039).

Optimizing results and improving their relevance is an example of deep learning, where we create our own neural network in which the algorithm works. It is worth noting that since the accuracy of the algorithm increases with the increase in the number of Likes, the longer we use Facebook, the more predictable we are for its algorithms. The algorithm "believes" that we are determined and it is only a matter of time before we become predictable. One can say that we are really free before clicking on Like for the first time. The most problematic is that the more predictive we are to the algorithm, the less chance we can change our image. The amount of data we leave behind only consolidates this image of our personality. In other words, the algorithm is immune to change. Meanwhile, man is a dynamic being.

The algorithm treats us as if we were things, performs a static evaluation of our personality (Stewart and Logan 2014, pp. 84-85). But one point is puzzling, because it seems to show some inaccuracy in the operation of the algorithms. The content that appears after clicking on a new Like, post, movie, etc. quickly adapts in relation to the previously selected material, which gives the impression that the algorithm does not create an unchanging image of the social media user along with the number of digital footprints, but that the algorithm reacts dynamically to our activity on the Internet, it is sensitive to changes in user's behavior. This apparent inaccuracy can be explained by the existence of greedy algorithms and dynamic programming.

In the case of a specific user, the algorithms solve two tasks simultaneously: (1) profiling his personality on the basis of overall activity and (2) adopting the displayed content to the "here and now" activity. The first task has the general goal of creating a permanent, digital image of a real person, from which conclusions can be drawn about political views, sexual orientation, alcohol consumption, etc. These are sensitive data used by politicians in election campaigns, corporations, and in general can serve to predict consumer preferences. The second task is, for example, to show ads depending on the recently visited pages or clicks on Likes and it is not about linking the general profile of our personality with what we do here and now. An algorithm profiling our personality could have too many problems to predict exactly what we will click at any given moment. Therefore, in order to adapt, for example, the content of advertisements to what the user is doing at the moment, a different algorithm is used. These two tasks correspond in turn to dynamic programming (1) and greedy algorithms (2). Algorithms solve these tasks simultaneously, but they are two different algorithms, so there is no contradiction between the overall personality profiling and the currently prompted content to see.
The greedy algorithm is one "that makes a sequence of choices, each choice being in some way the best available at that time (the term greedy refers to choosing the best). When making the sequence of choices, a greedy algorithm never goes back on earlier decisions" (Curtis 2003, p. 125). This makes the greedy algorithm work quickly and locally optimally. In other words, the greedy algorithm wastes no time checking that the choice it makes agrees with the user's previous activity. The problem is that "in fact there are no natural greedy algorithm that works" (Kleinberg and Tardos 2005, p. 251). Why? From the user's point of view, the algorithm works because it shows them the content they are interested in at the moment, but such locally optimal results say nothing about the overall activity of people on the Internet and do not constitute a basis for "global" optimization and therefore also for predicting future user's behavior on the Internet based on their past activity on social media. In other words, greedy algorithms do not profile people and create their digital personality. Based on greedy algorithms, it would not be possible to create a technology that could read"honesty, personality, intelligence, sexual orientation, political orientation and violent tendencies", from a human face, which is currently possible (Kosiński 2021). Who might believe that greedy algorithms do not work? Creators of these algorithms who want to get more static, optimized results from which it is possible to infer about the invariable characteristics of people leaving their digital footprints. Due to the use of greedy algorithms, we have the impression that artificial intelligence is following our variability, but the use of dynamic programming ensures that all our digital footprints are optimized and used to create an unchanging and predictable image of a "digital" person.

Richard Bellman was the precursor of dynamic programming (Dreyfus 2002). It allows for the formulation of a subproblem (Dasgupta et al. 2006, p. 173). This makes it possible to optimize the results and make the algorithm immune to temporary changes. The term"dynamic" gives the impression that the algorithm reacts constantly to the user's behavior, while the dynamic aspect of dynamic programming should be understood in the light of the problem space. The algorithm responds to the user's behavior in such a way that it narrows down their personal profile so as to fit this behavior within the problem space. Therefore the algorithm is dynamic because it is responsive to the user's behavior, but it still creates the person's profile as static in relation to all their activities. The algorithm can "follow" the user's behavior and at the same time create their unchanging profile. How is it possible? Dynamic programming "explores the space of all possible solutions, by carefully decomposing things into a series of subproblems, and then building up correct solutions to larger and larger subproblems. (...) although it's systematically working through the 
exponentially large set of possible solutions to the problem, it does this without ever examining them explicitly" (Kleinberg and Tardos 2005, p. 251-252). Dynamic programming builds our current activity into the wider context of all the digital footprints we have left. This leads to another conclusion: a digital person is a deterministic being. ${ }^{1}$ Lack of awareness of this fact may mislead social media users as to their ability to mislead the algorithms.

The discussion about the existence of free will and determinism has also been taken up in recent decades by neuroscientists. This is particularly important because it was neuroscience that contributed, as we have seen, to the transfer of the concept of a neural network to computer science. It could be assumed that since the operation of algorithms leads to the determination of the behavior of a"digital person", i.e. a digital person appears as a deterministic entity, it will be similar in the case of its real prototype. Benjamin Libet's experiment seemed to confirm these assumptions. The rise of readiness potential occurred $-550 \mathrm{~ms}$ before taking action and $-200 \mathrm{~ms}$ before the awareness of the will to act (Libet 1985, p. 536). Free will seemed not to exist and to defend freedom of decision-making, Libet introduced the concept of conscious veto (Libet 1999, p. 53).

Later studies by A. Schurger, J. Sitt and S. Dehaene showed that brain activity can be reflected by a stochastic model:

"Here we present a very different interpretation of mounting neural activity preceding spontaneous movements made in the context of a spontaneousmovement production task. Our model shows that a decision threshold applied to autocorrelated noise - in this case the output of a leaky stochastic accumulator - can account for the specific shape of the RP as well as the distribution of waiting times from subjects performing Libet et al. $(9,15)$ spontaneous-movement task" (2012: E2904).

The conclusion that the brain functions stochastically rather than linearly and deterministically differs, in my opinion, from the assumptions for creating algorithms and profiling human personality based on Likes, which leads to attempts to predict the future behavior of a specific person.

\footnotetext{
1 Attempts are being made to show that the brain is a quantum computer. Posner molecules enable quantum processing (Fisher, 2015, p. 596). If the brain is a quantum computer, it could be described by both deterministic and probabilistic algorithms. If quantum algorithms were used in profiling the personality of social media users, the image of personality produced by these algorithms would perhaps be more reflective of the real person. But even then it is difficult to suppose that such a"quantum personality" would fully reflect the theological dimension of the human person.
}

The nondeterministic model also seems to be confirmed by economic research. Gary S. Becker showed that man behaves according to the "utility calculus" called an economic approach as follows:

"Everyone recognizes that the economic approach assumes maximazing behavior more explicitly and extensively than other approaches do, be it the utility or wealth function of the household, firm, union, or government bureau that is maximized. Moreover, the economic approach assumes the existence of markets that with varying degrees of efficiency coordinate the actions of different participants - individuals, firms, even nations - so that their behavior become mutually consistent" (1976, p. 5).

It would seem that the economic approach supports algorithmization in the understanding of human behavior. However, complete algorithmization is very unlikely, as morality (moral satisfaction) must be incorporated into the economic approach.

Even if we treat morality as a relic of natural selection (Sheets-Johnstone 2008, p. 64-652), there is no certainty that a particular person will stick to natural law in order to be able to assume this observance and incorporate it into a model predicting future behavior. What is more, on the grounds of morality, conscience, people change very often and are already"elusive" for the model they created by clicking on Likes. In summary, the issue of morality can be presented as follows (Fijałkowski 2013, p. 60):

$T U_{i}=\sum_{j=1}^{n} U j+\mathrm{UB}+\mathrm{UM}$

This equation shows the so-called total utility of individual (TUi), which consists of the following: sources of utility $\left(U_{j}\right)$, benefit of choice when it comes to respect the law or committing the offence $(U B)$, and moral enjoyment or unpleasantness depending on whether we decide to obey the law or break it $(U M)$. Rather, the emergence of the question of moral satisfaction and moral unpleasantness works against predictability. And it is not even about the origin of morality, but about its very existence. It creates the possibility of choice and thus introduces indeterminism in our behavior. Perhaps it is the indeterminism of human behavior, the unpredictability of the human person, is the deepest

\footnotetext{
${ }^{2}$ The author writes from the point of view of methodological naturalism:"A belief in personal immortality or in the immortality of 'the soul' is from an empirical perspective unwarranted" (SheetsJohnstone, 2008, p. 64). Roger Scruton responds to this approach by pointing out that certain traits of human personality and God as a person cannot be treated as mere objects (Wentzel van Huyssteen, 2017, p. 2).
} 
Table 1 Comparing a digital person with a real person

\begin{tabular}{|c|c|}
\hline Digital person & Real person \\
\hline - is deterministic, predictable; & - is partially determined and to some extent unpredictable \\
\hline - is describable by algorithms; & - is only partially algorithmic \\
\hline - operates on the basis of neural networks; & - creates neural networks of themselves \\
\hline $\begin{array}{l}\text { - has a large impact on the formation of a neural network, but with the } \\
\text { increase in the number of neurons, the possibility of influencing the } \\
\text { result of algorithms' operation decreases; }\end{array}$ & $\begin{array}{l}\text { - an increase in the number of neurons in a network does not affect the } \\
\text { ability to change and be unpredictable }\end{array}$ \\
\hline $\begin{array}{l}\text { - is treated more like an unchanging thing than a free and self-con- } \\
\text { sciousness being; }\end{array}$ & - it is fully self-consciousness and is not a thing \\
\hline $\begin{array}{l}\text { - the digital person's past has an extremely strong influence on the } \\
\text { predictability of their future behavior; }\end{array}$ & $\begin{array}{l}\text { - the past is of great importance, but does not determine the future of } \\
\text { the person, who remains to some extent unpredictable and changeable }\end{array}$ \\
\hline $\begin{array}{l}\text { - the future does not belong to a digital person, this person is rather a } \\
\text { slave of the past and cannot decide what to do in the future; }\end{array}$ & $\begin{array}{l}\text { - the future most certainly belongs to the person who is able to get away } \\
\text { from the past }\end{array}$ \\
\hline - does not produce Black Swans & - does produce Black Swans \\
\hline
\end{tabular}

reason for the appearance of the Black Swans described by Nassim (2020, p. 235-280).

Black Swans are a rare and unpredictable phenomenon. They resist all attempts at algorithmization, they cannot be seen in mathematical models. Aside from that, often these phenomena are triggered by natural events, just as often people are behind them. Behind the entire domain of economics are the people who create financial institutions, governments and economy. It seems that it is possible to predict what will happen and that our forecasts will be adequate to reality. And yet the Black Swans cannot be predicted and they have a huge impact on our lives. Models that predict the future are like Facebook algorithms: they assume reality works like a thing and avoid volatility. Importantly, this variability usually appears where there is a person. It can be assumed that the Black Swans are caused by us. The lack of determinism makes it difficult for us to model and predict events. The need for modeling and prediction helps us to make important decisions and come to terms with the fact that we live in Extermistan (term used by Taleb), where everything can be suddenly changed, then it does not fit into the algorithmic reality. What is more, we ourselves stop understanding each other because man has also become a digitized, predictable being. Trying by force the algorithms to move into the reality of real, non-digital people, they become merely a model approximating how societies work, provided that we treat societies as if they were made of things, not people.

I believe that in order to understand why we have such great difficulties with modeling, predicting and applying algorithms on a larger scale, one must take into account the transcendent dimension of man and return to the original concept of personhood. This incalculable personality dimension becomes clearer when spirituality, to some extent noncommunicability, individuality and mystery are taken into account. These characteristics of a person allow us to see what is invisible in models and make us not be surprised by the existence of Black Swans. In this light, the digital person is only a "substitute" of what the human person really is. When comparing a real person and a digital person, we see the following (Table 1).

The table shows that a real person is a different being than its digital counterpart. However, companies that use algorithms to know what consumers want are not based on who a real person is, but a digital one.

\section{The impact of the "digital person" on the life of a real person}

Using algorithms gives the impression that people are becoming predictable and it is easier, for example, to optimize or plan the company's operations. However, it seems that such a strategy may operate in the short term. If we treat man as a changeable and to some extent unpredictable being, then we should not assume that the neural network will always be adequate in relation to the man who created it about themselves. This is not the only reason that raises doubts, so that the algorithms distort the truth of the image of man. Not only that, the algorithms draw conclusions based on statistical reasoning (Mittelstadt et al. 2016, p. 4), but also the results of their operations may be inconclusive and unclear, if only because it is not fully known what data was used to draw conclusions (Mittelstadt et al. 2016, p. 4). Besides, the very operation of the algorithms seems to be opaque (Mittelstadt et al. 2016, p. 6-7). Perhaps it is the opacity that is the biggest problem. The general operation of algorithms may and is clear, but the purpose for which they operate is not clear anymore, as it depends on the engineer who established it.

The assumption to use algorithms to profile people gives a sense of objectivity because an algorithm is something that defies human guidance and produces more objective 
results. But even in deep learning, algorithms must, at least initially, be "made by hand". This means that an algorithm is just a very sophisticated method of getting information about people that the algorithm designer wanted to get from the beginning. Thus, the algorithm is, as it were, an extension of human cognitive abilities. The designed algorithm works according of its creator's will. This is where the ethical aspect comes in, because we don't know exactly what the creator of this technology was guided by. Moreover, the algorithm designer has a cognitive advantage over, for example, social media users, they can "see them through". Thus, having access to the results of the algorithm's work, someone obtains supernatural abilities to get to know another person without their knowledge. I believe some kind of "ethical oversight" is needed here.

If the algorithm is an extension of human cognitive abilities, it is worth asking the question what is the result of the algorithm's operation: information or knowledge? Distinguishing information from knowledge is an ambiguous task. It can be said that the two categories overlap somehow, although the information "may not always reflect the cognitive ability, the center of gravity lies in the management of this asset in the process of making rational decisions of allocation by consumers, businesses and a government" (Żelazny, 2015, p. 8). The question that arises concerns the "cognitive" abilities of algorithms. Does the algorithm only gather information, or does it also process it and make it organized in such a way that we can call it knowledge? Here I make a distinction between information and knowledge in the following sense: "Knowledge is a derivative of information" (Żelazny, 2015, p. 13). Information is prior to knowledge, it is its "building block". For the production of knowledge, we need an ordering factor that draws conclusions from the available information. We can assume that the information system itself is knowledge-creating, and this, in turn, indicates that the information creator acts rationally.

Regarding ethical issues, there seem to be at least two: (1) algorithms follow the pattern that was presented to them by the designer, which means that this pattern is how the algorithm is supposed to interpret and process information and make it knowledge. Consequently, this knowledge applies to users of e.g. social media and (2) these users are treated as objects, not persons. So we are dealing with human reification. As shown above, the pattern on which the algorithm can operate can be e.g. the Big Five model. Reification occurs in the sense that we assume that this model is always a true description of an individual's personality. We see a man through the model, and as long as the model seems to be internally consistent, so long as one does not change along with it. Theory does not take into account changes in reality, but reality is richer than it is. In the case of algorithms, there is no place for Gödel's incompleteness theorem. We see man as seen by the creator of the algorithm who uses an incomplete theory to understand man.

Now let us ask a question about the kind of knowledge obtained from the algorithm. There are basically two following solutions to the way of acquiring knowledge: a priori and a posteriori. So, what kind of knowledge we get as a result of the work of algorithms: a priori or a posteriori? If we define apriorism as "a type of epistemic justification that is, in some sense, independent of experience" (Russell 2020) and we will assume that this independence of experience is possible thanks to the knowledge of previously known premises, ${ }^{3}$ then we will be able to consider the predictions about the future behavior of social media users as a priori knowledge provided by the algorithm. Premises for this knowledge may be, for example, Facebook Likes, on the basis of which the algorithm will make conclusions. The conclusions are forward-looking and, therefore, deductive in nature. It is worth asking the question about the accuracy of such a priori knowledge in relation to reality. I think this question is especially important for economics, because the answer will show to what extent knowledge based on digital footprints can serve as a basis for economic predictions.

When it comes to models that predict how things work, using algorithms seems to be able to get pretty good results. Mathematical models are great especially for predicting linear phenomena and things whose behavior is characterized by relative invariability or axiomatic compressibility (Barrow 2018, pp. 31-35). The digital person is, in a sense, suitable for such algorithmic, linear processing. However, the real person is nondeterministic, has free will, and it is this factor that makes determinism time-dependent. In other words, the accuracy of the algorithms' predictions is the greater the closer to the future their forecasts relate to. In practice, this means, for example that setting up new companies and forecasting tax revenues is always burdened with risk the greater the further into the future these forecasts. Therefore, some economists propose to apply the chaos theory to describe the dynamics of changes in the free market (cf. Hayward and Preston 1999, pp. 177-180). Investors, however, do not like chaos, so politicians try to intervene in the free market and stabilize it, thus making it from nondeterministic to much more predictable and "algorithmic". The question is whether such an approach to solving the problem of unpredictability is moral?

\footnotetext{
3 Aristotle in the Posterior Analytics wrote:"Assuming then that my thesis as to the nature of scientific knowing is correct, the premises of demonstrated knowledge must be true, primary, immediate, better known than and prior to the conclusion, which is further related to them as effect to cause. Unless these conditions are satisfied, the basic truths will not be 'appropriate' to the conclusion" (Aristotle, $72 b)$.
} 
The policy of stabilizing chaos and making economic life more predictable leads to an increase in the role of the state and interventionism, and even to socialism. Friedrich August von Hayek wrote as follows:

"When individuals combine in a joint effort to realize ends they have in common, the organizations, like the state,that they form for this purpose, are given their own system of ends and their own means. But any organization thus formed remains one 'person' among others, in the case of the state much more powerful than any of the others, it is true, yet still with its separate and limited sphere in which alone its ends are supreme. The limits of this sphere are determined by the extent to which the individuals agree on particular ends; and the probability that they will agree on a particular course of action necessarily decreases as the scope of such action extends" (2006, p. 63).

Hayek emphasizes that the goals of the state are often inconsistent with the goals of its citizens, and at the same time the power of the state over the citizen is powerful compared to the power of the citizen over the state. Hayek shows that the state uses its power to limit the freedom of choice of its citizens (2006, p. 99). But why does the government reach for the concept of economic planning?

We find the answer in Hayek, who noted: “( ...) economic problems arise always and only in consequence of change. So long as things continue as before, or at least as they were expected to, there arise no new problems requiring a decision, no need to form a new plan" (1945, p. 523). No change means no problems. Hayek's next comment is particularly valuable for this paper:

"The belief that changes, or at least day-to-day adjustments, have become less important in modern times implies the contention that economic problems also have become less important. This belief in the decreasing importance of change is, for that reason, usually held by the same people who argue that the importance of economic considerations has been driven into the background by the growing importance of technological knowledge" (1945, p. 523).

Recognizing the importance of economic research goes hand in hand with the development of new technologies, and at the same time this development underestimates the importance of changes. It is noteworthy that Hayek's article was published two years after the work of McCulloch and Pitts, which emphasized the rational, logical nature of the biological human brain. The belief in human predictability goes back at least to the times when man began to be treated more like a mathematically descriptive thing than as a bodily and spiritual being. It has been enhanced by the development of artificial neural networks and algorithms, including backpropagation. It is not the fault of algorithms that they operate on the basis of mathematics, most often assuming a deterministic world, but rather of a man who believed in the possibility of using them to describe a person and their behavior that is assumed to be adequate with reality. What are the economic results?

Hayek emphasizes the underestimation of practical knowledge in favor of theoretical knowledge and the omission of "eminently useful functions based on special knowledge of circumstances of the fleeting moment not known to others" (1945, p. 522). It is worth paying special attention to these fleeting moments, because they decide about our lives at every moment. In these moments, it turns out who has the practical knowledge that can be used to run their business, who has the knowledge to produce and sell something. These moments determine the freedom of the free market, because the sum of these moments gives the impression of market self-regulation. Moreover, it is impossible to replace practical knowledge with theoretical knowledge. When trying to exchange these two knowledge, the practical (a posteriori) knowledge becomes a priori. Hayek points out that such communication of knowledge to the central government does not solve the following problem: "We cannot expect that this problem will be solved by first communicating all this knowledge to a central board which, after integrating all knowledge, issues its orders. We must solve it by some form of decentralization. But this answers only part of our problem. We need decentralization because only thus can we ensure that the knowledge of the particular circumstances of time and place will be promptly use" (1945, p. 524). It seems that the knowledge provided by the algorithms is centralized.

The reason I say this is not only because only a few people have access to it, but mostly because few people design algorithms that profile social media users according to a pattern created by engineers. The algorithm shows what the engineer wanted to see. Based on the knowledge generated in this way, companies receive an answer to the question previously asked by the engineer. It may be useful, but in the short term, for the following two reasons: (1) the real man changes and long-term descriptions may only concern what is unchanging; (2) such knowledge does not take into account the great complexity of the market and the situation in which the potential consumer is located, in which they make a decision. Following algorithms when identifying consumer preferences is somewhat similar to a centrally planned economy, with the difference that the source of knowledge about the economy is not the government, but an algorithm operating according to the pattern. Thus, the problems generated must be similar. I think the most important problem is that, as in the case of a centrally planned economy managed at the government level, similar in the case of algorithms, we are dealing with mathematical modeling deviating from reality. As in the case of central 
economy management, the knowledge needed for this task is transferred "from the bottom to the top", and in the case of using algorithms, we have a bottom-up course of knowledge. In a sense, it may appear that such knowledge is a posteriori and that its nature is inductive. However, I say that this is a priori knowledge.

The feature of a priori knowledge does not have to be that it is without experience, but above all that there are nonempirical states of knowledge (Judycki 1998/1999, p. 10) as well as necessity and "strict generality" (Judycki 1998/1999, p. 11). These two features of a priori knowledge can be found in the knowledge provided by algorithms. It is based on experience, but as such it is deductive, model. We apply such a priori-algorithmic knowledge to the market reality. The inconsistency between the inductive knowledge governed by the free market and the a priori knowledge provided by the algorithms results from differences in the objects to which we apply a priori and a posteriori knowledge. The digital person is indeed linearly descriptive, deterministic. But the real person is indeterministic, has free will, and is changeable. The solution to the difficulties in predicting this variability is, for example, a form of persuasion or manipulation, i.e. a kind of inversion of the cognitive process: instead of gaining knowledge about consumer preferences, consumers can be forced to buy what has already been produced. If persuasion is some form of advertising for high-quality products, it seems to be justified to some extent, while intrusive persuasion turning into manipulation is morally questionable. New systems such as Overton, SambaNova or Snorkel allow us to solve the problems we grapple with using algorithms. Let us take a look at them.

\section{Overton, SambaNova, Snorkel}

Overton has been designed to deal with the following three main challenges (Ré et al. 2019, p. 2-3):

1) Code-free Deep Learning,

2) Multitask Learning,

3) Weak Supervision.

Perhaps the biggest difference between traditional deep learning and Overton is that Overton does not use coding. The "Slicing Model" used by the system "allows the developer to identify fine-grained subsets of the input that are important to the product" (Ré et al. 2019, p. 3). The lack of coding is a very important advantage of the system as it avoids determinism. Deep learning algorithms are adequate for short-term predictions due to human variability. Overton does not rely on detereminating algorithms, but offers a more general perspective on the data approach. Overall, rather than focusing on algorithmizing the data, Overton relies on the data itself.

The system works on the basis of payloads and tasks. In the case of payloads

"Overton embeds raw data into a payload, which is then used as input to a task or to another payload. Overton supports payloads that are singletons (e.g., a query), sequences (e.g. a query tokenized into words orcharacters), and sets (e.g., a set of candidate entities). Overton's responsibility is to embed these payloads into tensors of the correct size, e.g., a query is embedded to some dimension, while a sentence may be embedded into an array of size $m \times d$ for some length $m$. The mapping from inputs can be learned from scratch, pretrained, or fine-tuned; this allows Overton to incorporate information from a variety of different sources in a uniform way" (Ré et al. 2019, pp. 4-5).

As for tasks "for each payload type, Overton defines a multiclass and a bitvector classification task" (Ré et al. 2019, p. 5). Overton can also work through TensorFlow and then "Overton takes the embedding of the payload as input, and builds an output prediction and loss function of the appropriate type" (Ré et al. 2019, p. 5). Overton was designed to be able to work on databases and, at the engineer's discretion, take into account the data that will be considered valuable in terms of the goal set. Thanks to this Overton is not limited to profiling and delivering a deterministic human image, but supervises a much wider range of data.

A slightly different purpose, but similar assumptions, guide the SambaNova system. Like Overton, SambaNova focuses on overseeing the work of deep learning applications. The system is based on e Reconfigurable Dataflow Architecture (RDU). I think that the general idea of this system is expressed in the following words:

"For many workloads, adequate computing power may be available. However, excess data movement leads to poor hardware utilization and intractable training times. As a result, researchers and developers often need to limit their algorithm designs to those that they can afford to train. In contrast, the SambaNova Reconfigurable Dataflow Architecture creates custom processing pipelines that allow data to flow through the complete computation graph. It uses a spatial programming model to optimize compute layout and minimize data movement to achieve high hardware utilization" (SambaNova, 2021, p. 4).

It can be said that SambaNova allows to optimize data without limiting its inflow and thus overcomes the problem of data volume and makes the result even more adequate in accordance with the intention of engineers. What does it mean for a person-participant in the free market? 
Because it is about a large amount of data, it may be provided that the goal is not only the algorithmization of individuals, but the entire market. If we assume that the freedom of a particular person becomes limited by interdependence on other people, then with enough data collected from people in a given area, entire societies can be profiled. Then we focus on the generalization of results and obtain a general social cross-section based on data generated by people themselves. SambaNova enables much more input without memory limitations and oversees models in parallel while maintaining accuracy (cf. Choy 2020). All this makes SambaNova an incredibly powerful tool to be used in, for example, market forecasting. However, we still remain in the Gaussian model, because Overton and SambaNova rely on a large amount of data and, in a way, average (optimize) them and make us lose sight of the Black Swans. It also means that a person is not seen as freer than when using traditional algorithms. It becomes part of the whole, an optimized being fitted to the overall model.

The third system is Snorkel, developed since 2016 at Stanford University. Its operation is based on similar assumptions as the foundations of Overton and SambaNova. There are three main functions of Snorkel: labeling, transformation and slicing. Labeling is characterized as follows: "Snorkel then models and combines these noisy labels into clean confidence-weighted training labels" (The Snorkel Team 2019). Transformation regards the so-called "data augmentation", i.e. "the strategy of creating transformed copies of labeled data points to effectively inject knowledge of invariances into the model" (The Snorkel Team 2019). As you can see, transformation means discovering the invariants present in the model. Such an augmented model shows a higher accuracy compared to the original training data (Joglekar et al. 2020). Snorkel, therefore, focuses on what is the least characteristic feature of the free market-invariability, and gives us modeled knowledge. As the market over a wide area with a lot of its participants is less variable than a single person, it is an augmented model can actually be used for a time as a provider of valuable knowledge. The higher the accuracy of the model, the greater the likelihood of not noticing minor changes that may in fact be the source of Taleb's Black Swans and lead to another economic crisis. Slicing functions allow you to even see what you want, because "slicing functions enable users to heuristically identify slices or subsets of the training dataset that are critical for application performance" (The Snorkel Team 2019). It can be said that Snorkel's slicing functions strengthen our a priori approach to superimposing our models on reality.

Which companies may be interested in relying on the systems discussed? It seems that mainly the largest ones can derive the greatest benefits from these systems, because they are most interested in global reach and as much data and supervision as possible. The assumption is as follows: small companies are rather interested in the local market and therefore do not need huge amounts of data on the global market. Instead, they can collect data about specific consumers and their preferences which "allows a company to accumulate knowledge of customers' buying behavior, the company would be able to provide more tailored offerings, better service, and greater purchasing convenience - all of which buyers would be loath to forfeit" (Porter 2001, p. 68). However, large companies-by using the systems presented above-achieve an information advantage over the small ones and become even bigger - the Matthew effect of accumulated advantage. I believe that there is a real risk of monopolizing the market here. The focus is not on the availability of the free market, but on the availability of information. The market becomes a game of inequality and the advantage is gained by those who have access to a large amount of processed data. But you can also see an advantage in the following situation: if large companies need subcontractors to become even larger, these subcontractors gain access to some of the information that is in the hands of the largest players. The question remains unanswered to what extent having such knowledge about consumer preferences will "only" help in the supply of certain products, and to what extent will it become part of the real power, however, without democratic procedures. Porter writes as follows: "Internet technology may be able to fortify those advantages, by tying a company's activities together in a more distinctive system, but it is unlikely to supplant them" (2001, p. 78). By advantages Porter means competitive advantages, that is "unique products, proprietary content, distinctive physical activities, superior product knowledge, and strong personal service and relationships" (2001, p. 78). However, it seems that these activities by companies today focus mainly on getting knowledge through these systems in order to increase their competitive advantage over other companies.

Overton, SambaNova and Snorkel make the digital person part of the digital society. It is a society that is closer to real societies because, like them, it is partially deterministic and, therefore, predictable, mathematically describable, etc. The two main features that distinguish real from digital society are as follows:

1) Real society, like a real person, produces Black Swans, because sometimes small internal changes, imperceptible from the point of view of the whole society, can cause unpredictable social changes, positive or negative, such as economic crises;

2) the real society has an influence on politics, participates in elections and maintains its democratic system or become part of a totalitarian system. The social system requires periodic confirmations. Digital society, on the other hand, has no influence on the choice of govern- 
ment, because it is those who have not been chosen by anyone and who have access to technology.

\section{Conclusion}

The development of machine and deep learning technologies as well as systems such as Overton, SambaNova and Snorkel makes us reflect on the consequences of using these technologies for Internet users and entire societies. The digital person is a different "being" than the real person, just as digital society is not what we really live in. The constitutive features of a person are rationality and freedom. This is evidenced by the origin of the term "person" and modern brain research. Free and rational persons, in turn, create a free market that is to some extent predictable, but the freedom of those who create it makes it ultimately unpredictable. The methods of dealing with this market volatility seem to be effective either in short periods of time-deep learning algorithms, or they picture the whole society and lose sight of a specific person-Overton, SambaNova and Snorkel. There are ethical dilemmas with both algorithms and systems. Probably the most important issue to be resolved in the near future will be the availability to systems that provide access to knowledge giving a competitive advantage. Equal access to this knowledge will be crucial to the freedom of the free market.

\section{Declarations}

Conflict of interest The author declares no conflict of interest.

Open Access This article is licensed under a Creative Commons Attribution 4.0 International License, which permits use, sharing, adaptation, distribution and reproduction in any medium or format, as long as you give appropriate credit to the original author(s) and the source, provide a link to the Creative Commons licence, and indicate if changes were made. The images or other third party material in this article are included in the article's Creative Commons licence, unless indicated otherwise in a credit line to the material. If material is not included in the article's Creative Commons licence and your intended use is not permitted by statutory regulation or exceeds the permitted use, you will need to obtain permission directly from the copyright holder. To view a copy of this licence, visit http://creativecommons.org/licenses/by/4.0/.

\section{References}

Aristotle, Posterior Analytics. http://classics.mit.edu/Aristotle/poste rior.mb.txt. Accessed 19 Mar 2021

Barrow J (2018) Nowe teorie wszystkiego. W poszukiwaniu ostatecznego wyjaśnienia (trans. R. Kosarzecki), Kraków

Becker GS (1976) The Economic Approach to Human Behavior. Available at: https://www.pauldeng.com/pdf/Becker_the\% 20economic\%20approach\%20to\%20human\%20behavior.pdf. Accessed 22 Nov 2020
Biesaga T (2014) Godność osoby ludzkiej a normy etyczne. In: Stępień K, Gudaniec A (eds) Maryniarczyk A. Spór o naturę ludzką, Lublin, pp 567-583

Choy M (2020) A New State of the Art in NLP: Beyond GPUs. https://sambanova.ai/blog/a-new-state-of-the-art-in-nlp-beyondgpus/. Accessed 03 Apr 2021

Curtis SA (2003) The classification of greedy algorithms. Sci Comput Program 49:125-157

Dasgupta S, Papadimitriou CH, Vazirani UV. 2006. Algorithms. San Diego

Dreyfus S (2002) Richard Bellman on the birth of dynamic programming. Oper Res 50(1):48-51

Fijałkowski K (2013) Rola psychologii w ekonomicznej teorii zachowań ludzkich Gary'ego S. Beckera Econimics 4(25):54-63

Fisher MP (2015) Quantum cognition: the possibility of processing with nuclear spins in the brain. Ann Phys 362:593-602

Hayward T, Preston J (1999) Chaos theory, economics and information: the implications for strategic decision-making. J Inf Sci 25(3): 173-182

Joglekar M, Hancock B, Chen VS, et al. (2020) Snorkel Intro Tutorial: Data Augmentation. https://www.snorkel.org/use-cases/02-spamdata-augmentation-tutorial. Accessed 04 Apr 2021

Judycki S (1998/1999) Wiedza a priori - struktura problemu. Roczniki Filozoficzne $46 / 47$ pp. $1-32$

Kleinberg J, Tardos E. 2005. Instructor Solutions Manual for Algorithm Design. Pearson

Kosiński M, Stillwell D, Graepel T (2013) Private traits and attributes are predictable fromdigital records of human behavior. PNAS 110(15):5802-5805

Kosinski M (2021) Facial recognition technology can expose political orientation from naturalistic facial images. Sci Rep 11:100. https://doi.org/10.1038/s41598-020-79310-1

LeCun Y, Bengio Y, Hinton G (2015) Deep learning. Nature 521:436-444

Libet B (1985) Unconscious cerebral initiative and the role of conscious will in voluntary action. Behav Brain Sci 8:529-566

Libet B (1999) Do We Have Free Will? J Conscious Stud 6(8-9):47-57

McCulloch WS, Pitts WH (1943) A logical calculus of the ideas immanent in nervous activity. Bull Mathl Biophys 5:115-133

Mittelstadt BD, Allo P, Taddeo M et al. (2016) The ethics of algorithms: Mapping the debate. Big Data \& Society: pp 1-21

Nielsen M (2018) Neural Networks and Deep Learning. https://static. latexstudio.net/article/2018/0912/neuralnetworksanddeeplearning. pdf. Accessed 15 Nov 2020

Patrologiae cursus completus. https://archive.org/details/patrologia ecurs104unkngoog/page/n5/mode/2up. Accessed 05 May 2021

Porter ME (2001) Strategy and the Internet. Harv Bus Rev 79(3):63-78

Putnam H (1960) Minds and machines. In: Hook, S. Dimensions of Mind: A Symposium. New York, pp 138-164

Ratzinger J (1990) Retrieving the tradition. concerning the notion of person in theology. Communio 17:439-454

Ré C, Niu F, Gudipati P. et al (2019) Overton: A Data System for Monitoring and ImprovingMachine-Learned Products. https://arxiv.org/ pdf/1909.05372.pdf. Accessed 27 Mar 2021

Rescorla M (2020) The Computational Theory of Mind. The Stanford Encyclopedia of Philosophy (Fall 2020 Edition). Edward N. Zalta (ed.), https://plato.stanford.edu/archives/fall2020/entries/ computational-mind/.

Richard of St. Victor De Trinitate (1855). In: J. P. Migne (ed.) Patrologiae Cursus Completus, tomus unicus, https://books.google. $\mathrm{pl} /$ books $? \mathrm{id}=$ PcYUAAAAQAAJ $\&$ printsec $=$ frontcover $\& \mathrm{hl}=\mathrm{pl} \&$ source $=$ gbs_ge_summary_r $\&$ cad $=0 \# \mathrm{v}=$ onepage $\& \mathrm{q} \& \mathrm{f}=$ false. Accessed 29 Oct 2020

Rosenblatt F (1961) Principles of Neurodynamics: Perceptrons and the Theory of Brain Mechanisms. New York 
Rumelhart DE, Hinton GE, Williams RJ (1986) Learning representations by back-propagating errors. Nature 323(9):533-536

Russell B (2020) A Priori Justification and Knowledge. The Stanford Encyclopedia of Philosophy (Summer 2020 Edition). Edward N. Zalta (ed.), https://plato.stanford.edu/archives/sum2020/entries/ apriori/

SambaNova Systems Inc (2021) Accelerated Computing with a Reconfigurable Dataflow Architecture. https://sambanova.ai/wp-conte nt/uploads/2020/12/RDA-Whitepaper.pdf. Accessed 02 Apr 2021

Schurger A, Sitt J, Dehaene S (2012) An accumulator model for spontaneous neural activity prior to self-initiated movement. PNAS 109(42):E2904-E2913

Sheets-Johnstone M (2008) The Roots of Morality. University Park

Taleb NN (2020) Czarny Łabędź. Jak nieprzewidywalne zdarzenia rządzą naszym życiem (trans. Olga Siara). Poznań
The Snorkel Team (2019) Introducing the New Snorkel. https://www. snorkel.org/blog/hello-world-v-0-9. Accessed 03 Apr 2021

Von Balthasar HU (1986) On the concept of person. Communio 13:18-26

Von Hayek F (1945) The use of knowledge in society. Am Econ Rev 35(4):519-530

Von Hayek F (2006) The Road to Serfdom. New York

Żelazny R (2015) Information society and knowledge economyessence and key relationships. J Econ Manag 2:5-22

Publisher's Note Springer Nature remains neutral with regard to jurisdictional claims in published maps and institutional affiliations. 